\title{
INTERNAL CONTROL OF DRUG INVENTORY AT THE PHARMACY INSTALLATION OF THE DUMAI CITY GENERAL HOSPITAL
}

\author{
Muhammad Amrin Hakim \\ Public Finance Accounting Study Program, Bengkalis State Polytechnic \\ Jl. Bathin Alam, Sungai Alam, Bengkalis, Riau, Indonesia 28711 \\ E-mail: rosmida@polbeng.ac.id; muhammadamrinhakim23@gmail.com
}

\begin{abstract}
This study aims to find out how the implementation of internal inventory control in the medicine (pharmaceutical) section of the Dumai City General Hospital which is located on Jalan Tanjung Jati No 4. Dumai City Regional General Hospital. This study uses descriptive analysis of the results of interviews with specified sources, field observations and documentation. Primary data were obtained from interviews and direct observations. While secondary data from documents related to drug supplies such as invoices, purchase invoices, receipt documents, inventory cards, expenditure documents, organizational structures, and letters of order. The results of this study indicate that the internal control of the supply of medicines is quite good and has not entered the very good category because there are several things that must be improved, namely the separation of duties that are listed in detail and there are still not carrying out according to procedures and the existence of arrears in payments to pharmaceutical companies and communication between related parties must be improved and improvements are still needed such as the addition of security devices and the area where the warehouse must be enlarged.
\end{abstract}

Keywords: Internal Control, Drug Inventory, Dumai City Hospital.

\section{INTRODUCTION}

In the current era, the government focuses on the welfare of the people, especially in the health sector. Therefore, public health services are required to improve their quality. This is because the hospital has become a necessity for the entire community. Likewise, the Dumai City Regional General Hospital (RSUD), as one of the hospitals, has a very important role in improving public health in the Dumai City area. The Dubai City Regional General Hospital (RSUD) is a hospital owned by the Dumai City government, which has been designated as a Regional Public Service Material (BLUD) based on the decision of the Mayor of Dumai No. 380/RSUD/2009 regarding the status of the Dumai City BLUD-RSUD. The determination as a hospital as a Regional Public Service Agency is following the requirements of the Law of the Republic of Indonesia No. 44 of 2009 on chapter 5 article 7 paragraph (3). To improve quality and services in the health sector and gain the community's trust, the Dumai Regional General Hospital tries its best to serve and provide for the community's needs related to medical services and drug supply services.

Inventory is a significant part and is one of the most extensive parts of current assets (Sebayang, et al., 2020). Inventory is also the most sensitive asset to damage, theft, and decline in market value. Without an optimal supply, the agency will face the risk that the agency will not be able to meet consumer demand one day. Inventory internal control can be carried out with security measures to prevent deviant actions. Damage, incorrect entry, failure to record requests, goods that are not issued that do not match the order, and all other possibilities that cause inventory records to differ from the actual inventory in the warehouse. Because there are several types of products and mobility in and out of goods, it is feared that there will be loss or theft of stock of goods; as a result, reasonable internal control is needed to avoid fraud in carrying out tasks. For this reason, periodic inventory checks are needed on inventory records with actual calculations.

According to the news online Riaupos.co, Dumai City Hospital lacks availability of patent medicines, based on the observation of Riau Pos at the Dumai City Hospital, making many residents complained about the empty supply of medicines such as cholesterol, blood pressure, heart problems, and others. This causes residents to buy medicines at outside pharmacists, and there have been queues in the morning to get these medicines. Another problem experienced by the hospital were poor service at the Dumai city hospital, namely related to the strike action carried out by doctors. This 
strike is a misunderstanding in the appointment of the health committee by the Dumai city hospital as the doctors feel they are not involved in setting the Dumai city hospital committee. Related with the background above, the authors are interested in researching "Internal Control of Inventory of Medicines on Installation the Pharmacy of the Dumai City Regional General Hospital."

\section{LITERATURE REVIEW}

According to Mulyadi (2014) and Hall (2011), internal control is generally a part of each system used as operational procedures and guidelines for a particular company or organization. Companies generally use the Internal Control System to direct the company's operations and prevent misuse of the system. The definition of internal control proposed by many authors is generally derived from the definition made by COSO (The Committee of Sponsoring Organizations of Treadway Commission). For example, in the book COSO (Schandl \& Loster, 2019).) defines Internal Control as follows: "Internal control is a process, effected by an entity's board of directors, management, and other personnel, designed to provide reasonable assurance regarding the achievement of objectives relating to operations, reporting, and compliance."

According to COSO's definition of internal control, it can be understood that internal control is a process because it penetrates the organization's operational activities and is an integral part of basic management activities. Internal control can only provide reasonable assurance, not absolute desire. This confirms that no matter how well the internal control is designed and operated, it can only provide adequate assurance; it cannot be fully effective in achieving the internal control objectives even though it has been designed and structured in such away. Even though the ideal internal control is well designed, its success depends on competition and constraints rather than implementation and cannot be separated from various limitations.

Objectives of internal control the internal control system consists of policies and procedures designed to provide management with reasonable assurance that it has achieved its goals and objectives (Mirosea \& Hasbudin, 2012). These policies and practices are often referred to as controls and collectively make up the entity's internal control. According to Arens et al. (2015: 340), "management usually has three general objectives in designing an effective internal control system". The Committee of Sponsoring Organization of The Treadway Commission (COSO) is a commission whose purpose is to research fraud in financial reporting (fraudulent on financial reporting) and make recommendations for public companies, independent companies, auditors, and educational institutions.

The components of internal control, according to COSO, as quoted from Kumaat (2011), include:

\section{Control Environment}

The control environment creates an atmosphere of control within an organization and affects the organization's awareness of authority. The control environment is the foundation for all components of internal control that make up the discipline and structure.

\section{Risk Assessment}

Risk assessment involves a dynamic and interactive process to identify and assess risks to achieve objectives. Risk is understood as a possibility that an event will occur and affect the achievement of the entity's goals. The chance to accomplish all entity objectives is considered relative to the established risk tolerance. Therefore, risk assessment forms the basis for determining how the organization should manage risk.

\section{Activities Control}

According to COSO, activities control are the acts specified through the policies and procedures that help ensure that management directives reduce risks to achieving the goals. Control activities are performed at all entity levels, at various stages in the business process, and over the technology environment. Control activities have a variety of purposes and are applied to multiple organizational actions and functions. Control activities include different activities, such as 
authorization, verification, reconciliation, analysis, work performance, safeguarding company assets, and segregation of functions.

4. Information and Communication

COSO explained that information is very important for each entity to carry out the internal control responsibilities to support its objectives.

\section{Activity Monitoring}

Monitoring activities by COSO is an evaluation activity with some form, whether nature continuous, separate or a combination of both are used to ascertain whether each of the five components of internal control affects the functions of each element, exists and functions.

COSO describes the relationship between the five objectives and the components of internal control in the form of a cube as above. Based on the figure, it is explained that there is a direct relationship between the objectives as what the entity wants to achieve with the components of internal control that represent what is needed to achieve those objectives, as well as the entity's organizational structure at each level (division, unit, operation, function, and others). The three categories of objectives (operations, reporting, and compliance) are represented by columns, then the five components of internal control are represented by rows during the organizational structure of entities.

Data collection techniques in this study are as follows.

\section{Observation}

Sugiyono (2014) states that observation is the basis of all knowledge. Observation is observing and recording directly or indirectly or formally or informally on the research object. This is done to complete the secondary data obtained from the Dumai City Regional General Hospital.

\section{Interviews}

According to Sugiyono (2014), two-person interviews are meetings to exchange information or ideas through questions and answers to construct meaning in a particular topic.

\section{Documentation}

Sugiyono (2014) states that document study is a qualitative data collection method in documentation to make research more credible. The documentation in this research is photos of observations and interviews and secondary documents obtained from the Dumai City Regional General Hospital.

\section{METHODOLOGY}

The data analysis method in this research is descriptive qualitative analysis. Hikmawati (2017) states that qualitative descriptive analysis is an analysis that uses benchmarks. Research that uses a lot of descriptive qualitative analysis is evaluation research that aims to assess how the variables studied follow predetermined benchmarks.

This type of research uses descriptive qualitative. According to Satori (2012), descriptive qualitative research is a step to describe an object, phenomenon, or social setting of translation in narrative writing. The data is facts collected in words or pictures rather than numbers. For example, this study intends to identify and describe the causes of empty drug supplies in the Dumai City General Hospital.

\section{Understanding Internal Control}

According to Mulyadi (2014), "the internal control system is defined as an internal control system that includes the organizational structure, methods and coordinated measures to maintain corporate wealth, check the accuracy and reliability of accounting data, encourage efficiency and encourage management policies. The definition of the internal control system emphasizes the objectives to be achieved and not on the elements that make up the system. Thus, the purpose of internal control 
above applies to companies that process information manually, with bookkeeping machines, or with computers.

\section{Elements of Internal Control}

Committee of Sponsoring Organization of The Treadway Commission (COSO) is a commission that aims to research fraud in financial reporting (fraudulent on financial reporting) and make recommendations related to it for public companies, independent auditors, and educational institutions.

\section{Internal Control over Inventory Internal}

Control over inventory is necessary, considering this asset is classified as relatively current. Let's talk about internal control over inventory. There are two main objectives of implementing the internal control: securing or preventing company assets (inventory) from theft, fraud, misuse, and damage and ensuring the accuracy (accuracy) of inventory presentation in financial statements (Subandi \& Basana, 2021). It includes control over the legality of purchase and sale transactions of merchandise.

\section{RESULTS AND DISCUSSION}

Data in this study were obtained through in-depth interviews with employees of the Dumai City Regional General Hospital related to drugs or pharmaceuticals, direct observation of the activities carried out in the procurement of drug supplies, and documentation in the form of photos and also checking documents related to the supply of medicines. Interviews were conducted on three sources, namely:

1. Azizah S.fam (Head of Pharmacy Installation), explaining the overall activities in the procurement of medicines supplies.

2. Ardi syahputra (Head of Pharmacy Warehouse) explained the activities that occurred in the management of drug supplies.

3. Nurul Althfunnisha (Pharmaceutical Administration Executive)

From the research results above, these are the respondent's data needed to support this thesis.

In the interview, there were 24 questions posed to the respondents involved to find out information related to the internal control of the Dumai city general hospital.

\section{Management of Drug Inventory for the Pharmacy Installation of the Dumai City Regional General Hospital}

Inventory management procedures carried out at the pharmaceutical installation of Dumai City Hospital consist of Inventory Planning Procedures, Inventory Procurement Procedures, Inventory Storage Procedures, and Inventory Distribution Procedures. However, sometimes the pharmaceutical installation of the Dumai City Hospital carries out the procedure for returning supplies to the distributor. In the following, a description of the inventory management procedures obtained from the research guided by the Standard Operation Procedures (SOP) for the pharmaceutical installation of the Dumai City Hospital is described. In addition, the drug supply planning procedure in planning the procurement of pharmaceutical supplies needs to be considered:

a. Disease patterns

Health workers must first know the distribution pattern of disease and the factors that influence the occurrence of the disease so that it can be understood how to prevent and suitable drugs for the disease.

b. Community capacity

Health workers must also look at the community's ability to buy medicines so that no price is too expensive.

c. Community culture

It is the most important factor for people in choosing between prescription and over-the-counter drugs, which is influenced by the price of the drug. In addition to economic factors, several factors 
also influence advertising, drug effectiveness, the severity of disease, physical form of drug, drug safety, and the ability of drugs to cure several diseases.

\section{Procedure for Procurement of Drug Supplies}

To ensure the quality of pharmaceutical services, the procurement of pharmaceutical supplies must go through official channels following applicable laws and regulations. The need for drugs in hospitals can be divided into routine and non-routine needs. Routine needs are based on basic needs, while non-routine needs are requests for a new type of drug. Based on the SOP for the pharmaceutical installation of the Dumai City Hospital, there are procedures for purchasing medicines and medical consumables (BMHP) as follows:

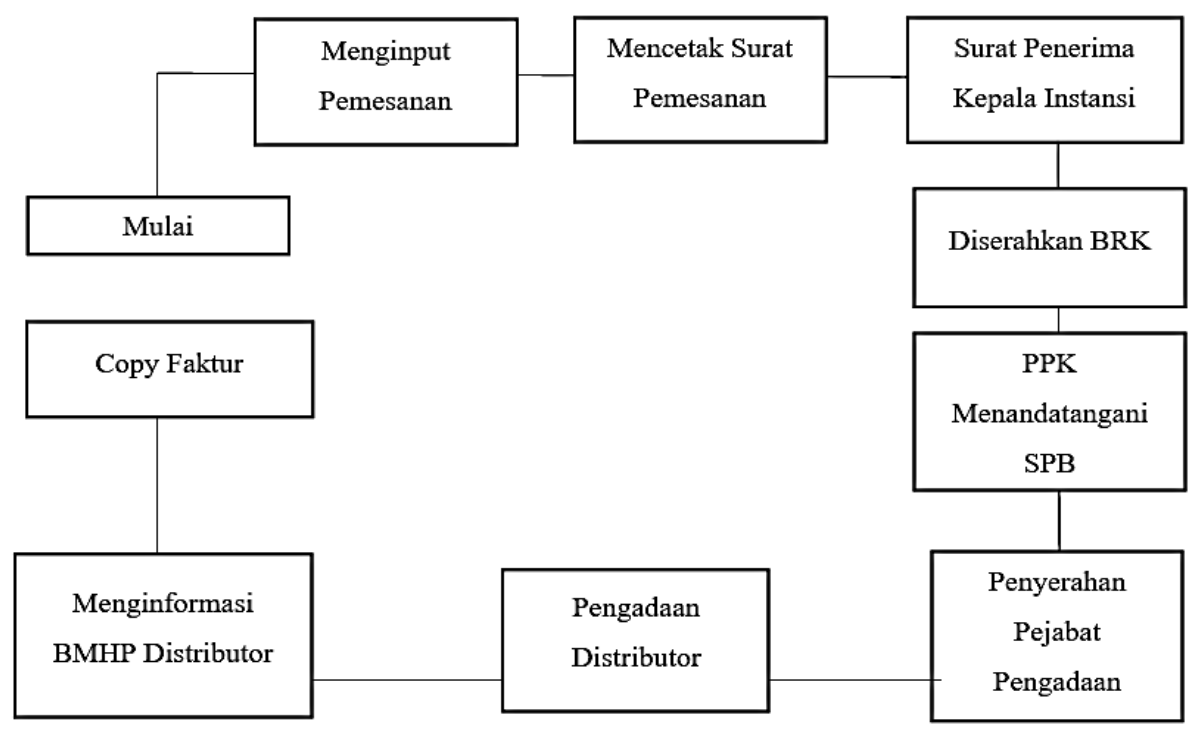

Figure 1. Procedure for Procurement of Drug Supplies

a. Pharmacists input drug orders and consumable medical bodies.

b. Pharmacists print goods order.

c. Receipts are handled by the head of the installation.

d. Goods receipt is submitted to stock exchange for activity plan.

e. Commitment maker signs Letter of Goods Receipt (SPB).

f. PPK presents SPB to procurement official Procurement.

g. Official signs SPB.

h. Procurement official sends SPB to distributor.

i. Procurement official confirms if drug or BMHP cannot be ordered to head of pharmaceutical installations to be replaced with an ordering goods receipt to the distributor who provided.

j. Pharmaceuticals provide copy of invoices for drugs, or BMHP entered a warehouse.

\section{Procedure for Inventory Drug Agencies Dumai City Hospital Pharmacy}

Interest drug storage is good, and the right is to maintain the nutritional quality of drugs, avoid irresponsible use, maintain the availability of drug stocks, and make it easier to search and control.

1. Drugs and medicinal substances must be stored in the original container from the manufacturer in the case of an exception or emergency where the contents are transferred to another container. Therefore, it must prevent contamination, and clear information must be written on the new container, the container at least containing the name of the drug, number batch, and expiration date.

2. All medicinal ingredients must be stored in appropriate conditions and ensure stability. Medicines generally have a time limit of use. After a specific time limit, it should not be used again. This is caused by chemical processes and drug compounds that can change the function and efficacy 
of the structure and ingredients. Therefore, the Dumai City Hospital dispensing drugs uses the FEFO (First Expire First Out) system to release the medications with the closest expiration date.

\section{The Procedures for Distribution of Drug Supplies at the Dumai City Hospital}

The department directly responsible for distributing and administering these drugs is the pharmaceutical installation section of the Dumai City Hospital. Pharmacy installation is a means of supporting health services in the management of health drugs, medical devices, and chemicals. The distribution of drugs at the Dumai City Hospital first starts from:

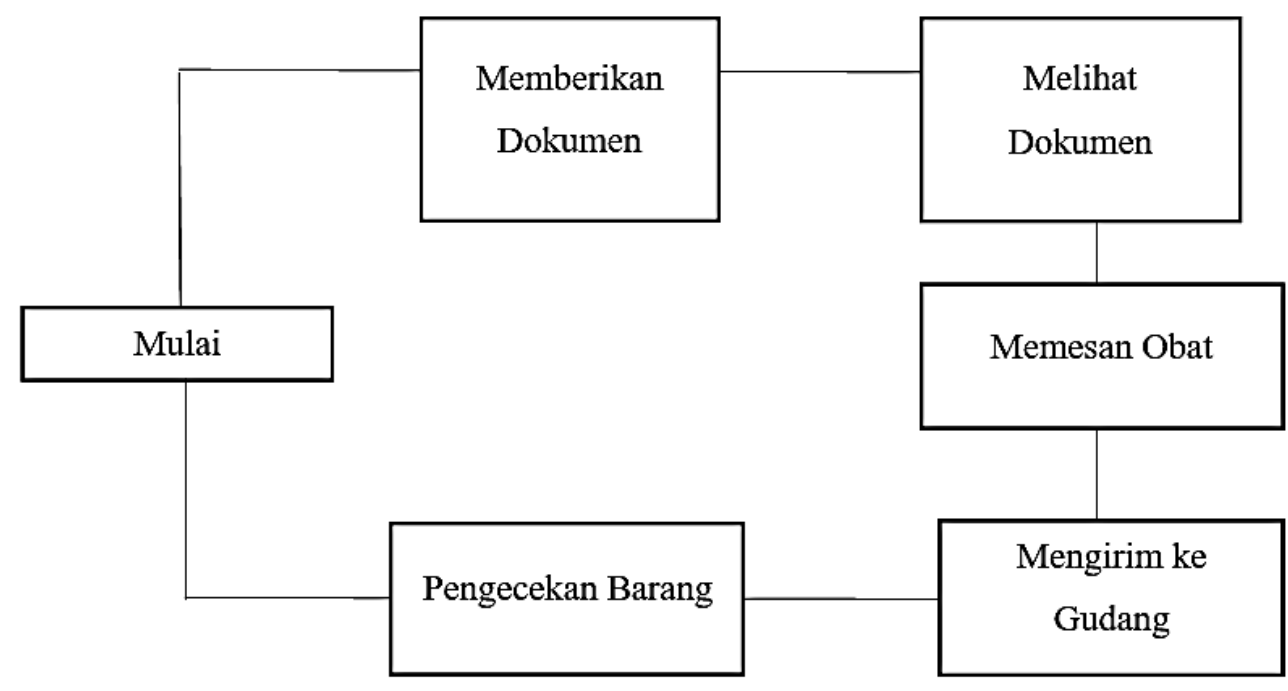

Figure 2. The Flow of the Drug Supply Distribution Procedure

a. All room staff provide a drug drop request document to the pharmacy department, which the room officer has filled in.

b. Pharmacy department looks at the requested document; if the inventory in the warehouse already exists, then the pharmacy asks the warehouse to prepare it.

c. If there is no inventory in the warehouse, then the pharmacy will order the drugs requested by all room officers to the drug company that has been determined.

d. If the drugs that have been ordered have arrived, the pharmacy will send the drugs to the warehouse.

e. The warehouse party must check the goods that have arrived and must be adjusted to the receipt. The drugs are arranged according to the storage temperature, alphabetically, by shape, then issued according to the request from the room.

\section{Procedure for Returning Drug Inventory to Distributor}

Returning drug supply from warehouse to distributor is the process of returning goods to a distributor for goods that are approaching the expiration date, damaged and withdrawn by BPOM because they do not meet the standards or requirements for safety, quality efficacy, and labels. The following is the procedure for returning drugs to distributors:

a. Warehouse officers record that the form is archived as outgoing goods on the return form.

b. Warehouse clerk submits the item to Pharmaceutical Wholesaler (PBF)

c. Warehouse officer asks for a letter to the distributor (for drugs) recall)

d. Proof of return from PBF is kept.

e. Distributor submits the return note and evidence of a return to PBF.

f. The warehouse officer records the return note that comes in the return form by filling in the return note's number, date, and value.

g. The return note is deducted from the next invoice for payment and replaced with goods worth return note. 


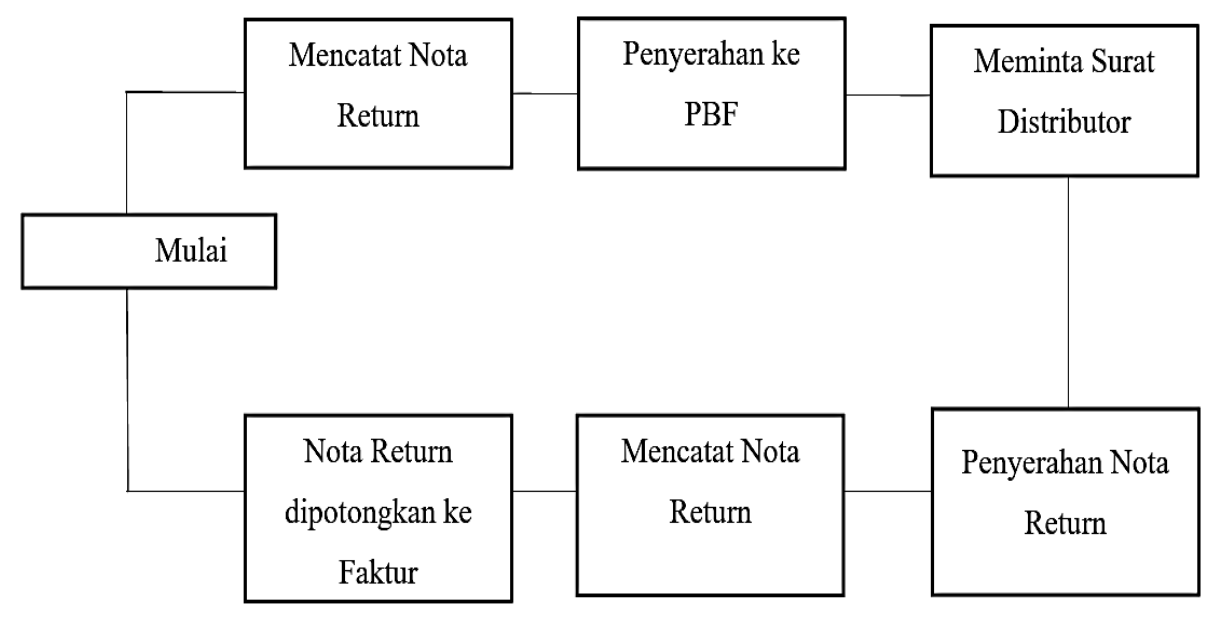

Figure 3. The flow of Procedure for Return of Distributor Drug Inventories

\section{Implementation of Internal Control Elements in Pharmaceutical Institutions at the Dumai City Hospital}

The implementation of internal control elements is seen from the Coso component to determine the percentage and feasibility that has been applied through the Champion formula (Champion, 1990).

Table 1. Percentage of Internal Control Elements

\begin{tabular}{clcc}
\hline \multirow{2}{*}{ No. } & \multicolumn{2}{c}{ Internal Control System } & \multicolumn{2}{c}{ Description } \\
\cline { 3 - 4 } 1. & Control Environment & 3 & No \\
2. & Risk Assessment & 3 & 1 \\
3. & Information and communication & 3 & - \\
4. & Control activities & 3 & 2 \\
5. & Monitoring and monitoring & 3 & 2 \\
& Total & $\mathbf{1 8}$ & $\mathbf{6}$ \\
\hline
\end{tabular}

The table above explains that several questions are answered yes and no. Questions that are answered with yes explain the questions asked to have been implemented or have been implemented appropriately and adequately. On the other hand, questions answered "no" are questions that have not been implemented or are not appropriate. Champion formula is used to determine the percentage of eligibility (Champion, 1990).

Rufus is an analysis carried out comparing the respondents' answers with the number of respondents. The analysis results are used in the form of numbers, then described and interpreted in a description and process in a way summed and compared with the expected number and percentage obtained. The calculation is based on a source using the Champion formula. The following percentages are:

Percentage $=\frac{\text { Number of Answers }}{\text { Total of yes answers }} \times 100 \%$

Percentage $=\frac{19}{24} \times 100 \%=75 \%$

1. $0 \%-25 \%$ means that the application of accounting is not good that the implementation of accounting is not good.

2. $25 \%-50 \%$ means accountability accounting is not good

3. $50 \%-75 \%$ means the application of accounting is quite good

4. $75 \%-100 \%$ means the application of accounting is excellent

The calculation of internal control of drug inventory at the pharmaceutical installation of Dumai City Hospital is categorized as sufficient, with a value of $75 \%$, so the implementation is quite good for the 
internal control of drug supply at the pharmaceutical installation of the Dumai City Hospital is in accordance with the elements of internal control according to COSO.

From the research results above, the discussion is specified using internal control components according to the theory of COSO. This method is expected to facilitate data analysis by categorizing based on internal control components.

The analysis can be described as follows:

1. Internal Control Environment. The control environment at the Dumai City General Hospital has been structured and disciplined. The Dubai City Regional General Hospital has a complete and structured SOP and organizational structure. However, the warehouse department on duty carries out the receiving, storing, and disbursing departments. There is no segregation of responsibilities for the three.

2. Risk Assessment. Work tools and physical protection of inventory are sufficient but security needs to be added such as finger scans for every employee going in and out of the warehouse. Employees have understood their respective duties and authorities because they have gone through training and have STR (Registration Certificate) to meet the expected competencies.

3. Control Activities. The documents have fulfilled or listed what was required. However, inventory accounting records are available, only glued to inventory cards and purchase invoices. Employees at the warehouse are not responsible for the loss and damage of medicines. Still, if these things happen, a crosscheck is held with the full authority and responsibility of the head of the pharmacy installation. SIM RS (Hospital Management Information System), a system used to control drug inventory, is integrated into all activities and transactions in the hospital.

4. Information and Communication. The RS SIM is used in all transactions in addition to existing records such as the Annual Drug Needs Plan (RKO), Hospital Budget, inventory cards, and others. The RKO is recommended to be updated more briefly according to the need for existing drugs.

5. Monitoring. Inventory cards are available at the warehouse to meet the needs of recording incoming and outgoing inventory. In addition, checks are carried out every two days by the head of the pharmacy installation and reported to the hospital director.

In the applicable SOP, inventory is divided into several parts, namely: fast-moving, slow-moving, and death stock. This means that medicines are treated according to the hospital's needs. In accordance with the SOP, the resource person, the Head of IFRS, stated that there had never been a run out of drugs and drug damage. Drug damage that occurs is likely to be very small and will not harm the hospital. RKO has an essential role in managing drug needs because RKO controls drug purchases and has been evaluated every period.

At Dumai City Hospital, the main operational functions, namely treatment and care for patients are carried out by the Functional Implementation Unit (UPF). Control over the supply of medicines at the Dumai City Hospital starts from planning the need for these medicines and continues until the procurement (purchase) and receipt of these medicines. The pharmacy installation as the unit planning the procurement of medicines must always hold consultations with doctors at UPF. For this reason, each UPF is asked to write down their needs according to their priority. The preparation of this list of drug needs must be guided by the hospital form that the Ministry of Health has determined. The pharmaceutical installation of the Dumai City Hospital does physical records once a month. The document used as the basis for recording drug dispensing is a stock card that matches the name of the drug or BMHP made by an Outpatient/Inpatient/IGD pharmacy officer.

\section{CONCLUSION AND RECOMMENDATION}

The conclusions from the research results include: all components of internal control established by COSO have been implemented quite well, thus it can be said that the internal control of inventory has been carried out effectively. However, several things need to be improved to support a better direction, such as segregation of duties, documents completion, and several tools that must be added to maintain medical supplies' safety. The internal control environment at the Dumai City 
General Hospital has been structured and disciplined. As of risk assessment, work tools and physical protection of inventory are sufficient but need to be added security such as finger scans for every employee going in and out of the warehouse. In terms of control activities, the documents have fulfilled or listed what was required. However, inventory accounting records are available, only glued to inventory cards and purchase invoices for information and communication. The RS SIM is used in all transactions in addition to existing forms such as the Annual Drug Needs Plan (RKO), Hospital Budget, stock cards, and more. The RKO is recommended to be updated more briefly according to the need for existing drugs. Monitoring (Monitoring). Inventory cards are available at the warehouse to meet the needs of recording incoming and outgoing inventory. In addition, checks are carried out every two days by the head of the pharmacy installation and reported to the hospital director.

\section{REFERENCES}

Arens, A. A., Elder, R.J., \& Mark, S. (2014). Auditing and Assurance service. Edisi keduabelas. Jilid Satu. Jakarta: Erlangga. Prentice Hall International. New York.

Champion, D. J. (1990). Methods and Problems of Social Research, Translation: E.

Hall, A. J. 2011. Accounting Information Systems, Edition 4, Jakarta: Salemba Empat.

Hikmawati, F. (2017). Metodologi Penelitian. Depok: Rajawali Pers.

Kumaat, V.G. (2011). Internal Audit. Jakarta: Erlangga Publisher.

Mirosea, N., \& Hasbudin (2012). The Role of Internal Control as A Part of Internal Audit in Implementation as the Legal Service Agency (Case Study in Haluoleo University, Indonesia). Jurnal Akuntansi, XVI (2), 293-307.

Mulyadi. 2014. Accounting System. Fourth Printing. Jakarta: Salemba Empat.

RiauPos.Co (2020). Patent medicine not yet available https://riaupos.jawapos.com/dumai/26/02/2020/225120/ obat-paten-belumcepat.amp..

Schandl, A., \& Loster, P.L. (2019). COSO Internal Control-Intergated Framework: A Implementation Guide for the Healthcare Provider Industy, https://www.coso.org/ documents/ coso-crowe-coso-internal-controlintegrated-framework.pdf.

Sebayang, P., Tarigan, Z.J.H., \& Panjaitan, T.W.S. (2020). ERP Compatibility on Business Performance through the Inventory System and Internal Integration. The 2nd International Conference on Advanced Engineering and Technology, 26 September 2020, Surabaya, Indonesia, 012008, 1-10.

Subandi, J. R., \& Basana, S. R. (2021). The Effect of Salience and Disposition Effect on Stock Investment Decisions on Investors in Surabaya. International Journal of Financial and Investment Studies, 1(2), 77-84. https://doi.org/10.9744/ijfis.1.2.77-84

Sugiyono. (2014). Metode Penelitian Pendekatan Kuantitatif, Kualitatif, dan R\&D. Bandung: Alfabeta.

Undang-Undang Republik Indonesia Nomor 44 Tahun 2009 Tentang Rumah Sakit 